\title{
Tüm barsaklar sana emanet: Truncus coeliacamesenterica
}

\section{Take care of all the intestines: Coeliacomesenteric trunk}

iD Büşra Pirinç ${ }^{1}$ (iD Alaaddin Nayman², iD Zeliha Fazlığulları ${ }^{1}$, iD Ahmet Kağan Karabulut $^{1}$

${ }^{1}$ Selçuk Üniversitesi, Tıp Fakültesi, Anatomi Anabilim Dalı, Konya

${ }^{2}$ Selçuk Üniversitesi, Tıp Fakültesi, Radyoloji Anabilim Dalı, Konya

$\ddot{O} z$

Truncus coeliacus ve a. mesenterica superior, gastrointestinal sistemin önemli bir bölümünü besleyen iki damardır. Bu iki damarın ortak bir kök ile aorta abdominalis’ten ayrılması nadir görülen ve oldukça önemli bir varyasyondur. 63 yaşındaki erkek hastanın 256 kesitli multidedektör bilgisayarlı tomografi anjiografi görüntüleri incelendi. Yapılan değerlendirmede truncus coeliacus ve a. mesenterica superior'un ortak bir kök halinde 1. lumbal vertebra'nın alt hizasında aorta abdominalis'in ön yüzünden ayrıldıkları tespit edildi. Bunun yanı sıra; a. gastrica sinistra'nın a. hepatica propria'dan orijin aldığı gözlendi. Truncus coeliacus'un varyasyonları karaciğer nakilleri, safra kesesi ve gastrik bölge cerrahisinin yanı sıra girişimsel radyolojik prosüdürlerde de oldukça önemlidir.

Kaynaklar: Truncus coeliacus - truncus coeliacomesenterica - varyasyon

\begin{abstract}
The coeliac trunk and superior mesenteric artery. are two vessels that supply a significant portion of the gastrointestinal tract. The separation of these two vessels from the abdominal aorta with a common stem is a rare and quite significant variation. 256 multidetector computed tomography angiography images of a 63 years old male patient were examined. In the evaluation, the coeliac trunk and superior mesenteric artery were separated from the anterior face of the abdominal aorta at the lower level of the first lumbal vertebra as a common trunk. In addition, it was observed that the left gastric artery originated from the hepatic artery proper. Variations of the coeliac trunk are highly important in liver transplants, gallbladder and gastric region surgery, as well as interventional radiological processes.
\end{abstract}

Key words: Coeliac trunk - coeliacomesenteric trunk - variation

\section{Giriş}

Truncus coeliacus (TC) ve a. mesenterica superior (AMS), aorta abdominalis'in ön yüzünden ayrılan visseral dallarıdır. TC, diafragmadaki hiatus aorticus'un hemen altında T12 ve L1 arasındaki intervertebral disk seviyesinde ayrilan ilk tek daldır (1) ve kisa bir seyirden sonra a. gastrica sinistra, a. splenica ve a. hepatica communis dallarına ayrılır. TC'un en sık görülen klasik sınıflaması trifurcation olarak bilinir ve ilk kez Haller tarafından tanımlanmış olup tripus Halleri olarak da ifade edilir. Bu patern günümüzde de TC'un normal dallanma paterni olarak kabul edilir (2). Bu dallar ile karaciğer, mide, pankreas ve duodenum'un üst parçasını besler (3). AMS ise, aorta abdominalis'in ön yüzünden ayrılan ikinci tek daldır ve ince bağırsak ile caecum, colon ascendens ve colon transversum'un büyük bölümünü besler (4).

TC'un klasik dallanmalarının dışında çeşitli varyasyonları görülmektedir, bunlar günümüze kadar pek çok araştırmaya konu olmuş ve bu varyasyonlar için farklı sınıflamalar tanımlanmıştır (1, 5-10). Bu sinıflamalarda, tipler TC'un klasik dallarının farklı şekillerde orijin kombinasyonları olabilirken (hepatosplenik, gastrosplenik, hepatogastrictrunk gibi $(7,9)$, TC'tan ekstra dalların orijin alması da gözlenmiştir (a. gastroduedonalis $(11,12)$ veya a. colica media $(11,13)$ gibi). Bu varyasyonlardan biri de TC ve AMS'un ortak bir gövde ile aorta abdominalis'ten ayrılmasıdır ve "truncus coeliacomesenterica" olarak isimlendirilir (5). Bu varyasyon ilk kez 1928'de Adachi (5)'nin sinıflamasinda yer alır. Bu siniflamada TC'un dallarıyla birlikte AMS'un orijininine göre altı tip bulunur ve tip 4 olarak truncus coeliacomesenterica tanımlanmıştır.

Truncus coeliacomesenterica, gastrointestinal sistemin ve karın iç organlarının büyük bölümünün beslenmesinden sorumlu olduğundan bu kökün herhangi bir patolojisinde ciddi komplikasyonlar gelişebilir. Bu nedenle oldukça nadir görülen bu varyasyonun tanınması sadece anatomistler için değil, klinikte cerrahlara ve girişimsel radyologlara tanı, tedavi, olası komplikasyonların önlenmesi ve nadir görülen problemlere sebep olabileceği için yararlı olacaktır. Bu çalışmada tesadüfen tespit edilen bir truncus coeliacomesenterica ve a. gastrica sinistra'nın farklı bir daldan kaynaklandığı bir vakanın görüntüleriyle

*7. Anatomi Kış Günleri’nde 21-23 Ocak 2019 tarihleri arasında Denizli’de poster olarak sunulmuştur.

Yazışma Adresi: Zeliha Fazlığulları, Selçuk Üniversitesi Tıp Fakültesi Anatomi Anabilim Dalı, Konya.

E-Posta: z_topal@yahoo.com

Alınma Tarihi: 04.06.2020 / Kabul Tarihi: 15.06.2020 / Yayımlanma Tarihi: 20.09.2021

Truncus coeliacamesenterica - Pirinç ve ark. 
detaylarını değerlendirmeyi ve klinik önemini vurgulamayı amaçladık.

\section{Olgu}

Rutin radyolojik değerlendirmeler esnasında bilgilendirilmiş onam formu alınan 63 yaşındaki erkek hastanın 256 kesitli multidedektör bilgisayarlı tomografi anjiografi görüntüleri incelendi. Yapılan değerlendirmede TC ve AMS'un ortak bir kök halinde 1. lumbal vertebra'nın alt hizasında aorta abdominalis'in ön yüzünden ayrıldıkları tespit edildi (Resim 1).

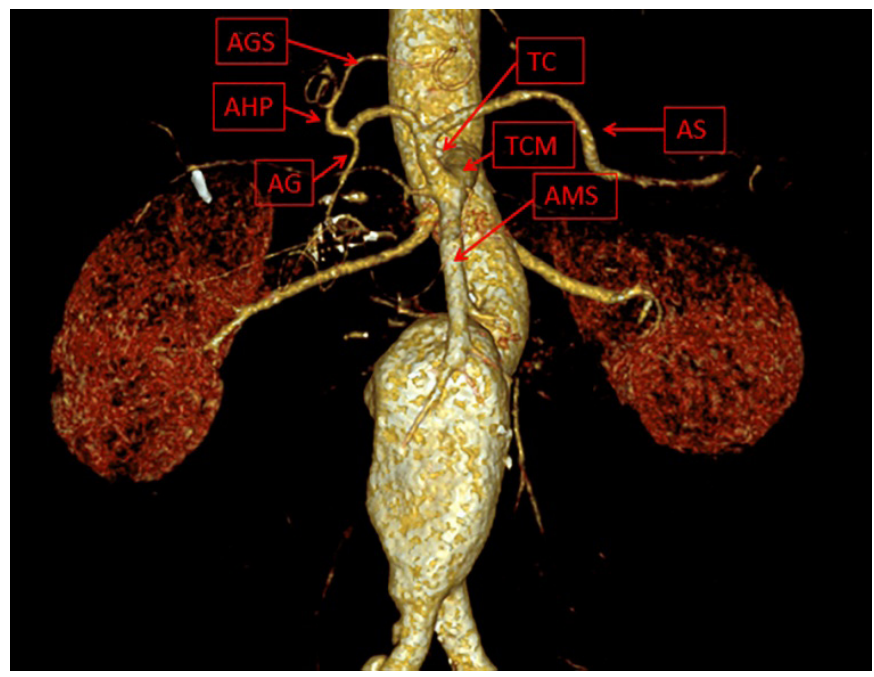

Resim 1: MDBT görüntüsünde truncus coeliacomesenterica'dan ayrılan truncus coliacus'un dalları ve a. mesenterica superior (TCM: Truncus coeliacomesenterica, TC: Truncus coeliacus, AMS: A. mesenterica superior, AS: A. splenica, AGS: A. gastrica sinistra, AHP: A. hepatica propria, AG: A. gastroduodenalis).

Truncus coeliacomesenterica'nın uzunluğu $2,72 \mathrm{~cm}$ ve çap 1 ise $1,06 \mathrm{~cm}$ olarak ölçüldü (Resim 2). TC'un ortak kökten ayrıldıktan sonra klasik dallanmayauygunolaraka.splenicavea.hepaticacommunis'inayrıldığ gözlendi. Normalde TC'un dalından biri olan a. gastrica sinistra ise vakamızda a. hepatica proria'dan orijin aldığ 1 tespit edildi (Resim 1 ).
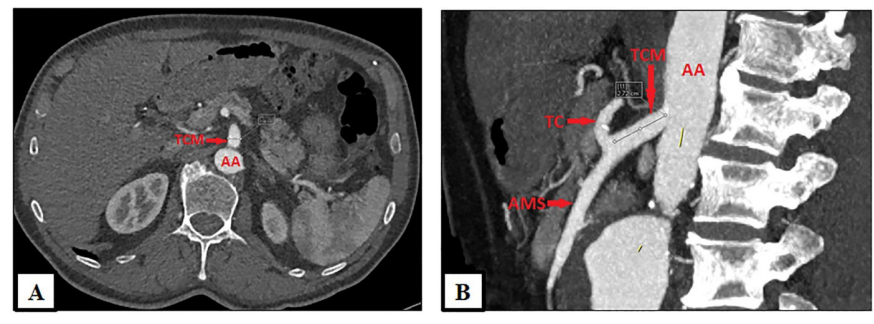

Resim 2: Tuncus coeliacomesenterica'nın çapı (aksial kesit) (A) ve uzunluğu (sagittal kesit) (B) (AA: Aorta abdominalis, TCM: Truncus coeliacomesenterica, TC: Truncus coelicus, AMS: A. mesenterica superior).

\section{Tartışma}

TC'un varyasyonlarının bilgisi, safra yolu operasyonları, karaciğer nakli, karaciğer tümörlerinin kemoembolizasyonu gibi üst abdominal bölgenin cerrahi ve girişimsel radyolojik prosedürlerini planlamak ve yürütmek için yararlıdır (6). Bu yapının normal dallanma paterninin sıklı̆̆ $1 \% 89$ olarak bildirilmektedir (12). TC'un varyasyonlarından biri olan truncus coeliacomesenterica, genellikle radyolojik görüntüleme veya anatomistler tarafından yapılan kadavra diseksiyonları sırasında tesadüfen tespit edilir ve bu varyasyonun çok çeşitli klinik etkileri vardır. Bu yapının zarar görmesi (darlık veya oklüzyonu) durumda gastrointestinal sistemin büyük bir kısmının kan dolaşımı tehlikeye girer ve karın içi organlarının çoğunu ciddi risk altında bırakabilir (14). Bu varyasyon tüm abdominal vasküler varyasyonların \%1'inden daha azı şeklinde bildirilmekte ve sıklığ $\% 0.25$ olarak kabul edilmektedir (15).

Truncus coeliacomesenterica'nın bilinmemesi ya da tanınmaması, girişimsel radyolojik işlemlerde ve cerrahide komplikasyonlara sebep olabilir ayrıca lig. arcuatum medianum sendromu (Dunbar sendromu, truncus coeliacus sendromu) gibi nadir problemlere yol açabilir. Bu bağ genellikle TC'un orijininin üzerinden geçer, ancak bazen bu bağ daha düşük seviyede bulunabilir ve truncus coeliacus'un proksimal kısmına bas1 yapabilir, bu duruma lig. arcuatum medianum sendromu (Dunbar sendromu, truncus coeliacus sendromu) denir (16). Truncus coeliacomesenterica'nın geniş bir kök olması ve konumu nedeniyle bu sendromun görülme riski bu varyasyonun bulunduğu vakalarda yüksektir (15). Bunun yanı sıra; TC sendromunun cerrahi tedavisi sırasında, yanlış damar ligasyonunu riskini önlemek için truncus coeliacomesenterica'nın varlığının akılda tutulması gerektiğine dikkat çekmiştir. Bu nedenle, oldukça nadir görülen bu vasküler paternin tanınması, abdominal cerrahiler ve transkateter tedaviler sırasında ilgili bölgedeki komplikasyonları en aza indirebilir (14).

A. gastrica sinistra, vakaların \% 90'nında TC'tan ayrılır, bu dal \% 60 - 100 sıklı̆̆ında bu yapının ilk dalıdır. A. gastrica sinistra, \% 0.5 - 15 sıklığında direkt aorta abdominalis'ten (17) ayrıldığı gibi çeşitli çalışmalarda a. splenica'dan (\% 6) (8), veya AMS'dan (\% 0.2) (18) da kaynaklandığ propria'dan ayrılan bu dal oldukça nadir görülen bir varyasyondur. Karaciğerin ve midenin beslenmesini sağlayan damarların anatomik yapısı ve varyasyonlarının bilinmesi hepatobiliyer ve gastrik bölgenin radyolojik değerlendirilmesinde ve cerrahisinde oldukça önemlidir (6, $9,19)$. Bu nedenle bu bölgeyi ilgilendiren ve oldukça nadir görülen vasküler varyasyonların bulunduğu olgu sunumumuzun, bölgenin vasküler anatomisi hakkında farkındalık oluşturması, girişimsel radyolojik ve cerrahi tedaviler sırasında komplikasyonların minimum düzeyde tutulması açısından çok değerli katkılar sağlayacağını düşünmekteyiz.

\section{Kaynaklar}

1.Marco-Clement I, Martinez-Barco A, Ahumada N, Simon C, Valderrama JM, Sanudo $\mathrm{J}$, et al. Anatomical variations of the celiac trunk: cadaveric and radiological study. Surg Radiol Anat. 2016;38(4):501-10.

2.Haller VA. Icones anatomicae in quibus aliquae partes corporis humani declineate proponuntur et arteriarum potissimum historia continetur. Gottingen - German: Vandenhoeck; 1765 .

3.Cicekcibasi AE, Uysal, II, Seker M, Tuncer I, Buyukmumcu M, Salbacak A. A rare variation of the coeliac trunk. Ann Anat. 2005;187(4):387-91

4.Gamo E, Jimenez C, Pallares E, Simon C, Valderrama F, Sanudo JR, et al. The superior mesenteric artery and the variations of the colic patterns. A new anatomical and radiological classification of the colic arteries. Surg Radiol Anat. 2016;38(5):519-27.

5.Adachi B. Das Arteriensystem der Japaner. Japanese: Verlag der Kaiserlich-Japanischen Universitat zu Kyoto; 1928.

6.Gielecki J, Zurada A, Sonpal N, Jablonska B. The clinical relevance of coeliac trunk variations. Folia Morphol (Warsz). 2005;64(3):123-9.

7.Lipshutz B. A composite study of the coeliac axis artery. Ann Surg. 1917;65:159-69. 
8.Michels NA. Blood Supply and Anatomy of the Upper Abdominal Organs with a Descriptive Atlas Philadelphia, Montreal: JB Lippincott Company; 1955

9.Panagouli E, Venieratos D, Lolis E, Skandalakis P. Variations in the anatomy of the celiac trunk: A systematic review and clinical implications. Ann Anat. 2013;195(6):501-11.

10.Uflacker R. Atlas of vascular anatomy: an angiographic approach. Baltimore: Williams \& Wilkins citied in the British Journal of Anatomy 2010

11.Chitra R. Clinically relevant variations of the coeliac trunk. Singapore Med J. 2010;51(3):216 - 9 .

12.Santos PVD, Barbosa ABM, Targino VA, Silva NA, Silva YCM, Barbosa F, et al. Anatomical Variations of the Celiac Trunk: A Systematic Review. Arq Bras Cir Dig. 2018;31(4):e1403.

13.Hemamalini. Variations in the branching pattern of the celiac trunk and its clinical significance. Anat Cell Biol. 2018;51(3):143-9.

14.Bhatnagar S, Rajesh S, Jain VK, Patidar Y, Mukund A, Arora A. Celiacomesenteric trunk: a short report. Surg Radiol Anat. 2013;35(10):979-81.

15.Varma KS, Pamidi N, Vollala VR. Common celiacomesenteric trunk: a rare anatomic variation. J Vasc Bras. 2009;8(3):271-3.

16.Aschenbach R, Basche S, Vogl TJ. Compression of the celiac trunk caused by median arcuate ligament in children and adolescent subjects: evaluation with contrast-enhanced MR angiography and comparison with Doppler US evaluation. J Vasc Interv Radiol. 2011;22(4):556-61.

17.Eaton PB. The celiac axis. Anat Rec. 1917;13(6):369-74.

18.Naidlch JB, Naidlch TP, Sprayregen S, Hyman RA, Pudlowski RM, Stein HL. The Origin of the Left Gastric Artery. Radiology. 1978;126(3):623-6.

19.Babu D, Khrab P. Coeliac Trunk Variations:Review With Proposed New Classification. Int J Anat Res. 2013;1(3):165-70. 